\title{
Production of Various Types of Poultry in Bulgaria for the Period 2010-2018
}

\author{
Assoc. Prof. Gergana Slavova PhD \\ University of Economics - Varna, Bulgaria \\ ggss@ue-varna.bg
}

\begin{abstract}
Poultry farming has always been a major part of animal husbandry in every country. Bulgaria is no exception and has a long-standing tradition in the breeding and production of various types of poultry. In reality, our country was mainly producing chickens, laying hens and eggs in the beginning, but was also successful in the breeding of ducks, turkeys, geese, yurts and other feathered more extravagant species, such as quails, ostriches, pheasants, etc. The main purpose of this article is to analyze the production of different types of poultry in Bulgaria for a sufficiently long period of 9 years, to be able to predict trends and changes that may occur in different types of poultry in the country and to determine not only which ones shall have a leading role for specific regions in Bulgaria, but also the ways to increase their effective production in the direction of closing the production and sales cycle with poultry products processing and reaching the end customer. The article uses methods of situation analysis, time series analysis, induction, deduction, extrapolation, trend derivation and logical dependencies, method of adding value and creating a final product.
\end{abstract}

Keywords: poultry farming, dynamics, change, trends, final product, closed sales cycle, chickens, hens, eggs, ducks, poultry

JEL Code: O12, O13, Q12, Q13, Q18

DOI: https://doi.org/10.36997/IJUSV-ESS/2020.9.1.3

\section{Introduction}

Out of all types of livestock breeding, known globally, poultry farming is one of the most intensive, from the perspective of the mechanization and automation of the production processes, which are utilized. This allows high level of efficiency of industrial production in the poultry breeding sector. Not only chickens and hens, but also many other types of poultry are farmed successfully in our country, including geese, turkeys, ducks, pheasants, ostriches, etc. (Kostandinov, I., 1997).

\section{Production of various types of poultry in Bulgaria in the past years}

Out of all types of livestock breeding, known globally, poultry farming is one of the most intensive, from the perspective of the mechanization and automation of the production processes, which are utilized. This allows high level of efficiency of industrial production in the poultry breeding sector. Not only chickens and hens, but also many other types of poultry are farmed successfully in our country, including geese, turkeys, ducks, pheasants, ostriches, etc. (Kostandinov, I., 1997). As at the end of 2018 and the start of 2019, Bulgaria farms a total of 15,519 thousand poultry - an increase of $5.2 \%$ compared to 2018. In total, 6,951 thousand hens and adolescent laying hens, 6921 chickens for meat production, 35 thousand turkeys, 1,408 thousand ducks, 13 thousand ducks and 191 thousand poultry are farmed in Bulgaria. A large portion of the hens farmed in Bulgaria are farmed for egg-laying purposes. This is evident from Table 1.

Approximately $60 \%$ of the laying hens and more than $80 \%$ of the chickens farmed for meat at the end of 2018 are farmed in the country's northern regions. We have to emphasize that they are being farmed under exceptionally humane measures in accordance with the norms of the European Union, the Rural Development Program, and most of all, particular Bulgarian scientists in this field (Belorechkov, 2011). The highest number of turkeys и ducks are farmed in the southern regions respectively $60 \%$ and $65 \%$ of the total number, and close to $70 \%$ of geese are situated in the Northeast Region of Bulgaria. The leading regions in egg production in 2018 are the Southern Central Region, North Central Region, and the Northeast Region. South Central Region takes up $25.2 \%$ of the total egg production, followed by the Northeast Region with $21.3 \%$. The first-ranked 
regions for production of chicken eggs for consumption in the country is South Central Region over the course of the period of analysis - with $29.4 \%$, followed by the North Central Region with $24.1 \%$ and by the Northeast Region - with $21.5 \%$.

Table 1. Production of eggs in 2018, distributed into planning regions, in thousands

\begin{tabular}{|l|r|r|r|r|}
\hline \multicolumn{1}{|c|}{ District } & $\begin{array}{c}\text { Eggs from } \\
\text { hens }\end{array}$ & Other eggs & $\begin{array}{c}\text { Total number } \\
\text { of eggs }\end{array}$ & $\begin{array}{c}\text { Change } \\
\mathbf{2 0 1 8} / \mathbf{2 0 1 7}\end{array}$ \\
\hline Northwest & 11963 & 589 & 120,219 & $-3,8 \%$ \\
\hline North Central & 325,672 & 1,621 & 327,293 & $6.0 \%$ \\
\hline Northeast & 275,763 & 729 & 276,492 & $-15,5 \%$ \\
\hline Southeast & 165,201 & 4,773 & 169,974 & $-7,9 \%$ \\
\hline Southwest & 65,720 & 11,014 & 76,734 & $6.8 \%$ \\
\hline South Central & 321,588 & 6,125 & 327,713 & $6.1 \%$ \\
\hline Total for the country & $1,273,574$ & 24,851 & $1,298,425$ & $-2,1 \%$ \\
\hline
\end{tabular}

Source: Ministry of Agriculture, Food and Forestry, "Agricultural Statistics" department, Agrarian Report for the year 2019

In table 2 herein below, we can analyze the production of poultry for the full territory of the country. Out of all poultry farmed in the country for the full period of analysis, the share of laying hens and young pullets is the highest, followed by chickens farmed for meat, and to a much lower degree - by the ducks. Turkeys, geese, quails, pheasants, and other poultry are farmed at much lower and insignificant quantities in Bulgaria.

Table 2. Farming of poultry in Bulgaria for the period 2010-2018

\begin{tabular}{|l|r|r|r|r|r|r|r|r|}
\hline Year & $\begin{array}{c}\text { Laying } \\
\text { hens and } \\
\text { young }\end{array}$ & $\begin{array}{c}\text { chickens } \\
\text { farmed for } \\
\text { meat }\end{array}$ & $\begin{array}{c}\text { Laying hens } \\
\text { and chickens } \\
\text { in total }\end{array}$ & \multicolumn{1}{c|}{$\begin{array}{c}\text { Turke } \\
\text { ys }\end{array}$} & Ducks & Geese & $\begin{array}{c}\text { Other } \\
\text { poultry }\end{array}$ & $\begin{array}{c}\text { Poultry } \\
\text { in total }\end{array}$ \\
\hline $\mathbf{2 0 1 0}$ & 7,800 & 6,263 & 14,063 & 158 & 1,628 & 56 & 29 & 15,934 \\
\hline $\mathbf{2 0 1 1}$ & 6,627 & 6,522 & 13,150 & 84 & 1,343 & 50 & 29 & 14,656 \\
\hline $\mathbf{2 0 1 2}$ & 6,338 & 7,499 & 13,837 & 47 & 1,297 & 26 & 53 & 15,260 \\
\hline $\mathbf{2 0 1 3}$ & 6,592 & 5,074 & 11,665 & 43 & 1,440 & 23 & 42 & 13,213 \\
\hline $\mathbf{2 0 1 4}$ & 6,815 & 6,155 & 12,970 & 45 & 1,517 & 21 & 56 & 14,609 \\
\hline $\mathbf{2 0 1 5}$ & 6,980 & 7,278 & 14,258 & 28 & 1,229 & 16 & 69 & 15,600 \\
\hline $\mathbf{2 0 1 6}$ & 7,158 & 5,290 & 12,448 & 32 & 1,128 & 17 & 75 & 13,700 \\
\hline $\mathbf{2 0 1 7}$ & 6,898 & 5,966 & 12,864 & 30 & 1,666 & 16 & 180 & 14,756 \\
\hline $\mathbf{2 0 1 8}$ & 6,951 & 6,921 & 13,872 & 35 & 1,408 & 13 & 191 & 15,519 \\
\hline
\end{tabular}

Source: Ministry of Agriculture, Food and Forestry, "Agricultural Statistics" department, Agrarian Reports for the period from 2010 to 2019.

\section{Production by species of poultry and regions}

It is important to note that this statistics varies from different country regions, for example the Northeast Region has the highest level of production for geese compared to all other regions in Bulgaria, but despite this fact, the main production for this region is poultry farming and poultry raising - hens for eggs, egg-laying hens and chickens (Rangelov et al., 2010). One of the largest poultry farms is situated in Donchevo village, Dobrich district - "Yaitsa i Ptitsi-Zora, Donchevo village". The next figure presents the farmed laying hens and shows their dynamic variation over the full analyzed period. A linear equation has been presented, which details their dynamic change, which suggests that the fluctuations and amplitudes in the production are small and insignificant. 


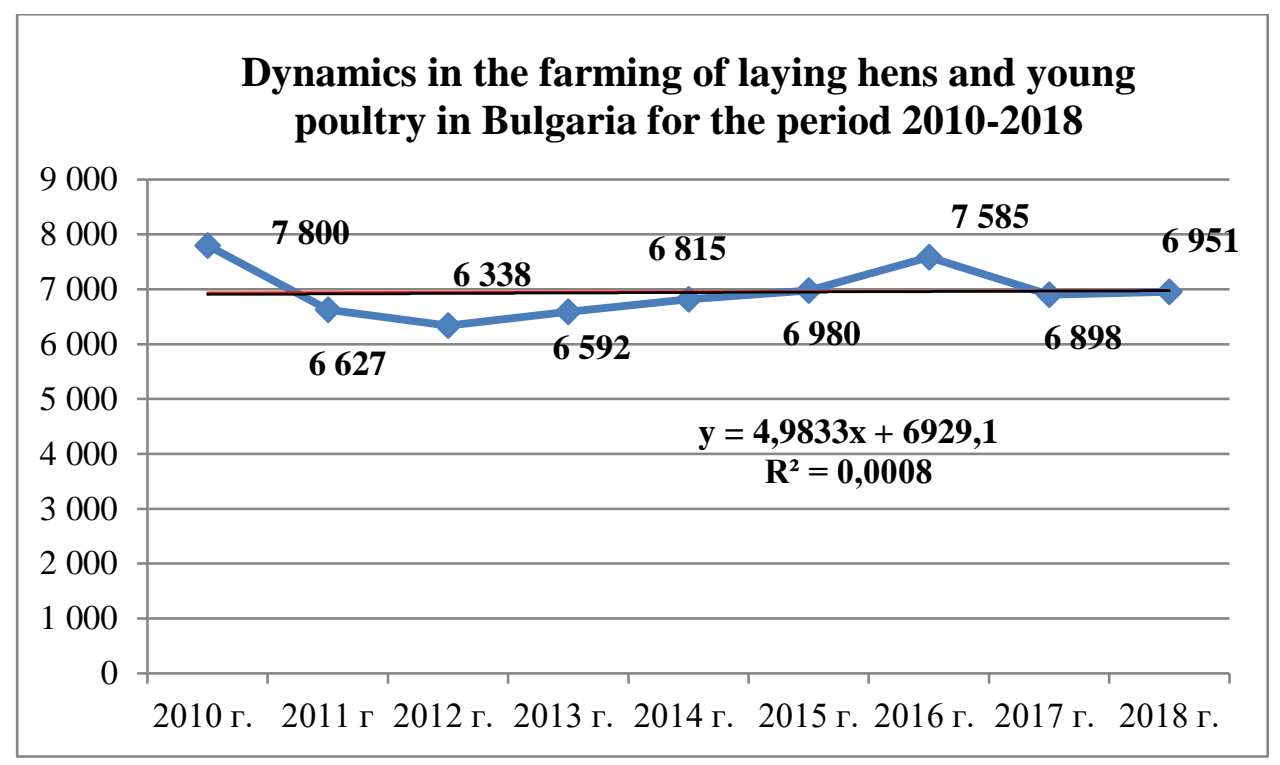

Figure 1. Dynamics in the farming of laying hens and young poultry in Bulgaria for the period 2010-2018.

Amplitude fluctuations and dynamic changes in farming chickens for meat are much more significant. This is evident from the second figure below. The explanation for the higher level of dynamics in their production is based on the fact that new companies are introduced in the sector, some of which are related to major German and French companies. A good example for a company of this type is "Pilko" OOD - Razgrad. It creates franchise relationships with part of the producers of poultry meat in Northern Bulgaria (in the region from Pleven to Varna), and supplies feed and everything they need to farm the chickens to those producers. The sole issue is that due to the faster drive for reproduction, chickens receive a lot of vaccines and growth hormones, which not only provide them rapid development, but immediate and unhealthy growth.

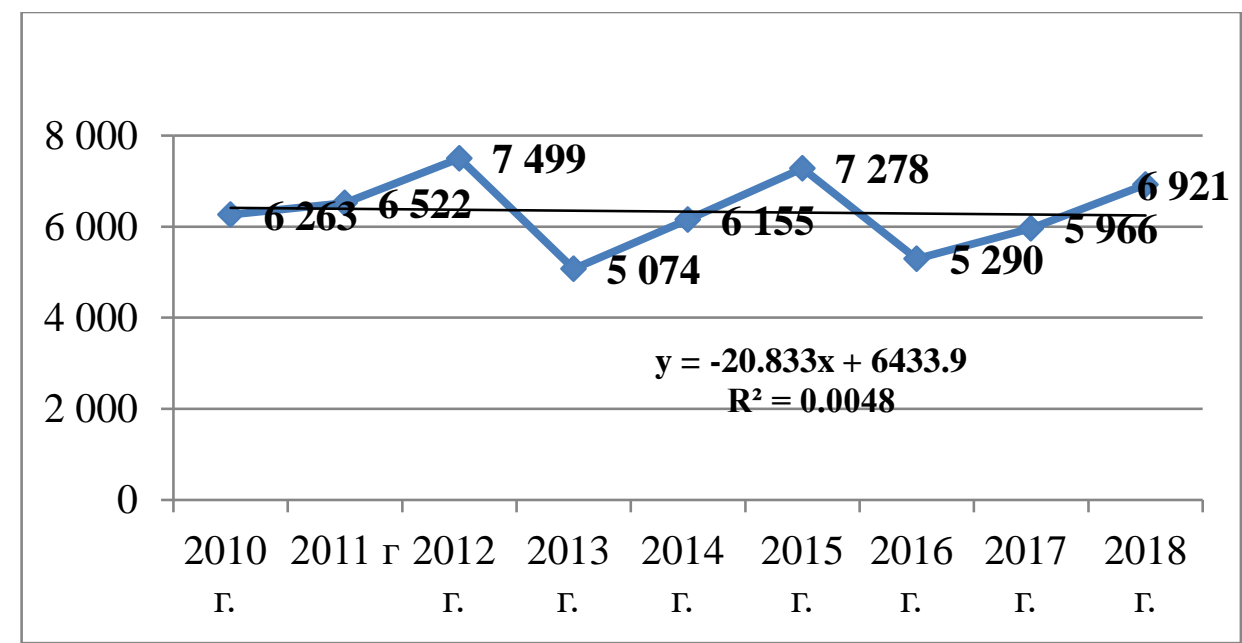

Figure 2. Dynamics in the farming of chickens for meat in Bulgaria for the period 20102018 in thousands of chickens

Figure two shows that the trend in farming chickens is ascending and is described in the most precise manner with a linear equation, and the stochastic error is very low. Figure three presents the dynamics in changing the farming and production of turkeys in the country for the analyzed period. Unlike the first two figures, the trend here is of extreme decrease, and only at the 
end of the period of analysis, an amplitude oscillation occurs, which points towards a slight increase. Farming turkeys is a more labor-intensive and less mechanized process; therefore, their production is much less developed in our country. It is expected to have low levels of change in follow-up future periods.

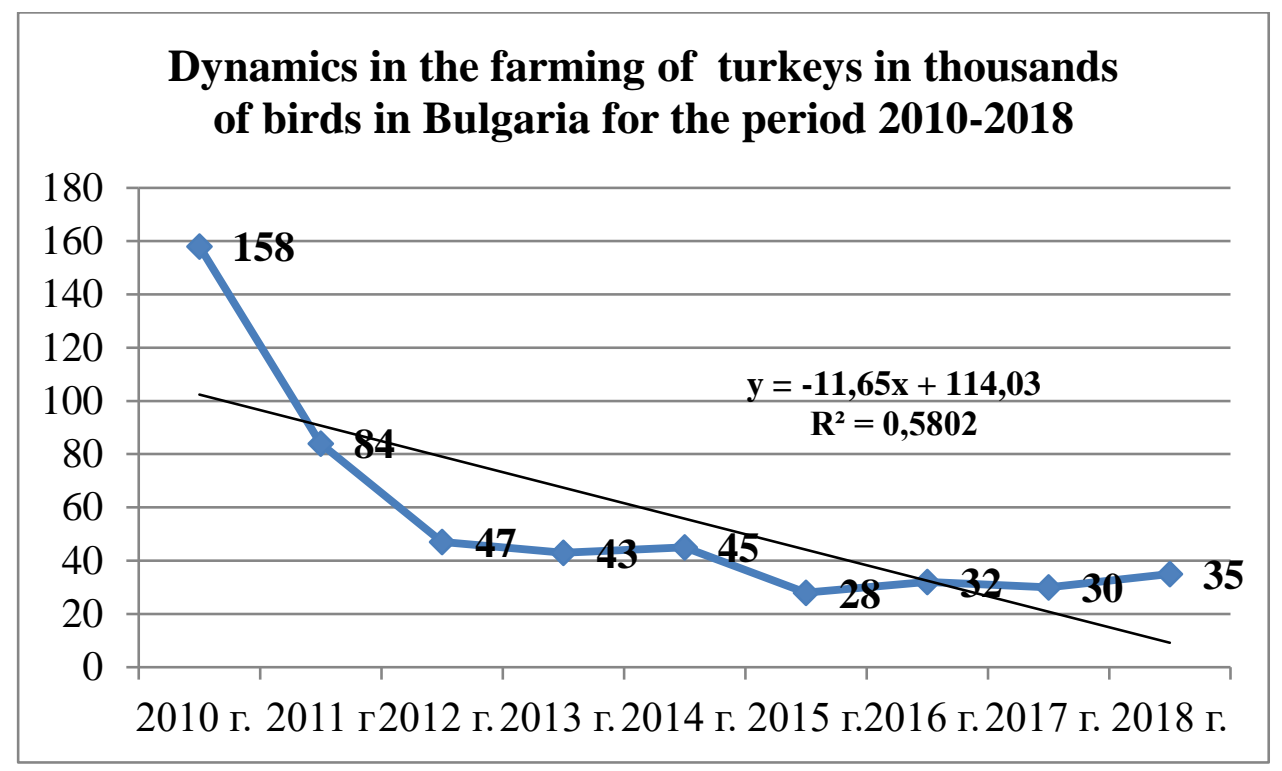

Figure 3. Dynamics in the farming of turkeys in thousands of birds in Bulgaria for the period 2010-2018

Unlike turkeys, the ducks farmed in Bulgaria as another type of main bird farming activity over the period of analysis has shown a much higher growth of production, and a much lower degree of dynamic changes, and in 2017-2018 the output has reached a peak of sorts, and has reached a degree higher than at the start of the period of analysis, and their dynamic change is best described with a linear equation.

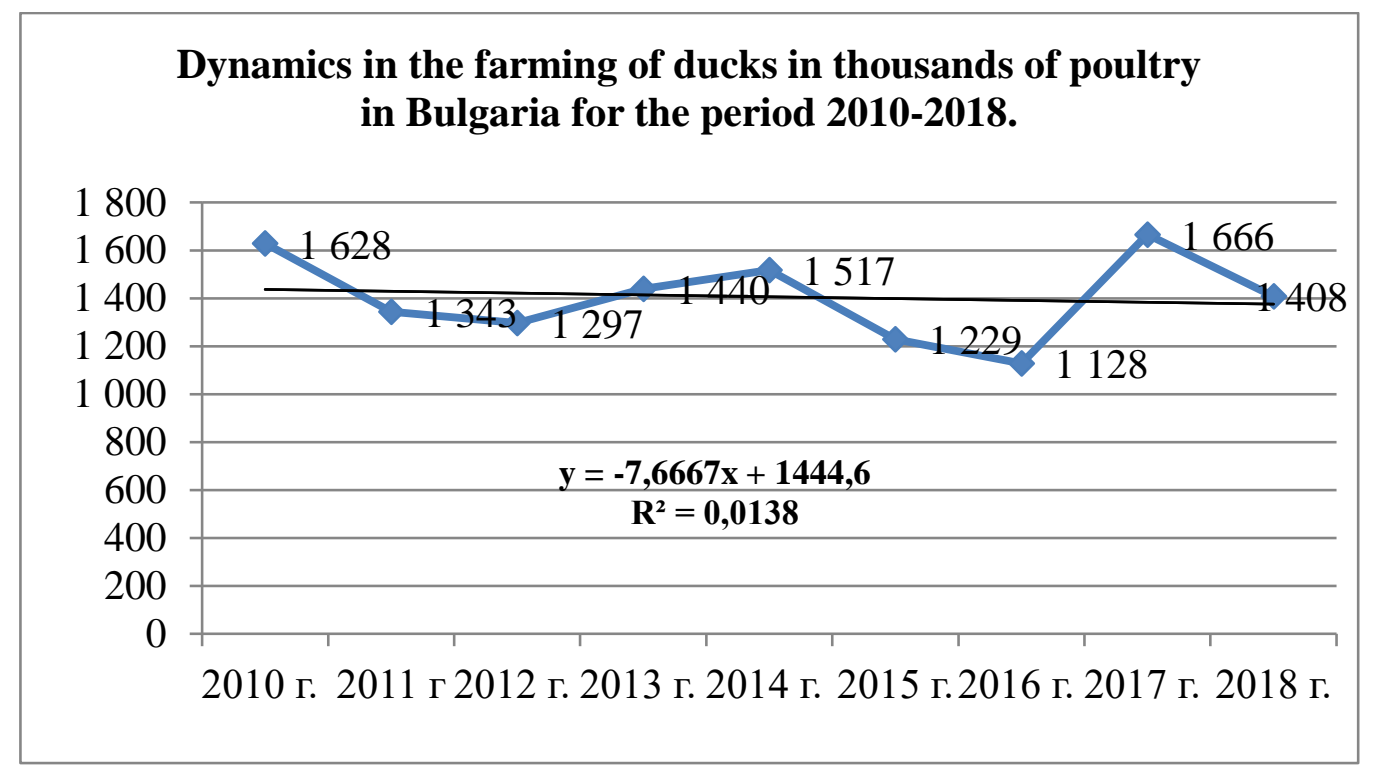

Figure 4. Dynamics in the farming of ducks in thousands of poultry in Bulgaria for the period 2010-2018 
The figure below showcases the changes in geese farming in Bulgaria for the nine-year period of analysis. The fact of a marked downward trend is very pronounced, which is explained by their more labor-intensive and not as highly automated production. Farming of geese, mostly for goose liver in Bulgaria requires serious capital investment, good labor force, excellent knowledge, and intensified veterinary medicine supervision. Therefore, the downward trend in the production of goose meat and goose liver in our country is not an unusual, but is also not a desired outcome, as this is one of the best opportunities for exporting gourmet meat and processed gourmet meat products outside of the territory of our country. The dynamic change in in the production of goose meat for the period of analysis is again best described with a linear equation, and unfortunately designates trends of ever-decreasing level of production of this gourmet type of meat in Bulgaria.

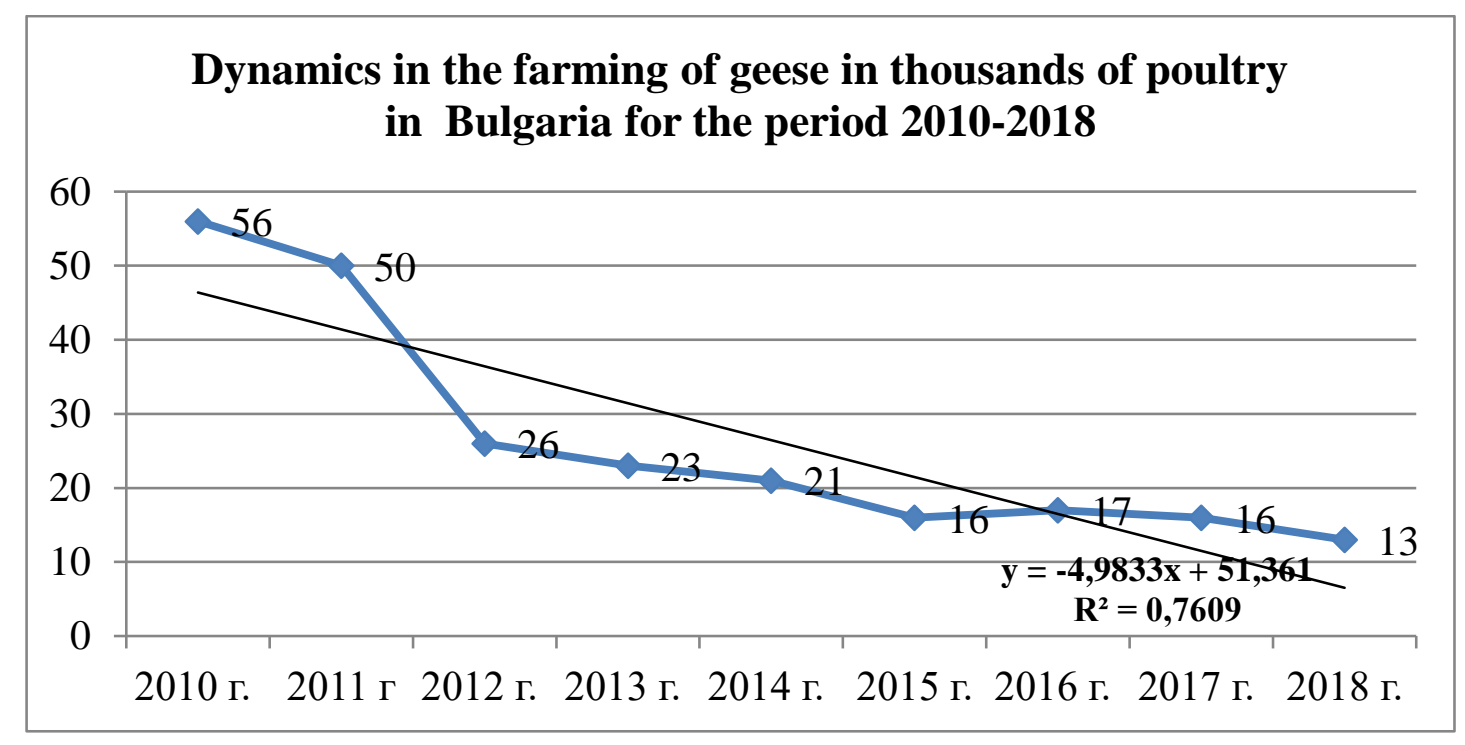

Figure 5. Dynamics in the farming of geese in thousands of poultry in Bulgaria for the period 2010-2018

When discussing the development of the poultry farming sector and the dynamic change of the main types of bird farms in our country, we cannot ignore a fact that would be strongly emphasized during the third programming period of the Rural Development Program. It connects to the idea of adding value to the produced agrarian material, in this case the meat output from different types of poultry could be processed and offered to end customers as a finished food product, ready for consumption. We can showcase good examples of this in particular companies from the Northeast Region of the country. One of those examples is Poultry farm "Zora" AD Donchevo village, which farms chickens and laying hens for eggs, but also creates egg mélange and other processed products, necessary for the food industry. Other very good examples are: Guzher Commerce EOOD, town of Popovo, sole trader "Vasil Ivanov-Shans 61" - Fattening of ducks, Varna district, Ptitseklanitsa AD-Dobrich, "Nasto-Pet" EOOD-town of Dobrich, farming of ducks and production of high-quality duck products from fattened ducks - Mular. The products which are produced by this company are predominantly gourmet products. As an example, we can showcase boiled chicken fillet, cold turkey fillet, duck breast fillet, smoked duck leg, duck liver pate and meat, and a series of other gourmet products, which are designated for consumers both on the domestic and on the foreign markets.

Adding value is in the form of processing the poultry meat material and the output is end 
products for consumers of poultry gourmet products. Such products may be, for example: short and long shelf life sausages, produced by poultry meat, including: sausages, debarcini, salami, also raw and boiled smoked fillets and other gourmet foods, production of pates and other chicken, duck and geese half-finished products, stipulated for the producers of poultry meat. The end product not only adds value and helps the producer get a higher profit margin, but it also adds value to the improved technologies used in the production process and the applied product and technological innovations. Creating specialized company stores is also a good option for reaching the end client and, to the extent possible, eliminating the role of the middleman companies, which do not allow producers in the country to realize sufficient profit margins from their farming poultry work in Bulgaria.

\section{Conclusion}

The completed general dynamic analysis of the development of poultry farming in Bulgaria over the course of the last nine years has shown that the highest rate of increase is the rate of farmed laying hens, chickens for meat and ducks. It has been established that the particular types of productions have an established trend toward preserving the respective increase or decrease in different types of poultry farming. In the production of chickens and laying hens, for example, we observe a permanent upward trend, whereas the farming of geese and ducks, we have a downward trend, and this development is expected to be preserved over the course of the next two years. All examples of good practices, showcased in the article, indicate that the Bulgarian producers have realized that poultry farming is only the first main part of their business, but it is also not sufficient. Therefore, production of processed poultry products in our country, in our opinion, is the main way in the future to make this sector be more stable and less dynamically variable, compared to the changes in the environment. The production of an end product, implementing by encompassing the production and the sales cycle and reaching end clients directly, will allow the realization of this goal in the future.

\section{References}

1. Belorechkov, D., 2011, Humane treatment in raising broiler chickens, publishing house "Enovche" S., page 32

2. Kostandinov, I., 1997, "Album of family farms for poultry farming and poultry breeds farmed in Bulgaria, Agricultural Sciences, publishing house Pensoft, S., pages 34-36

3. Rangelov, A., Ivanov, I., 2010, Intensive and free-range farming of turkeys, hens and broilers for eggs and meat, publishing house "Enovche", S., page 23-29

4. Ministry of Agriculture, Food and Forestry, "Agrarian Statistics" Department, Agrarian Reports from 2010 - https://www.mzh.government.bg/bg/politiki-i-programi/otcheti-i-dokladi/agrarendoklad/01.09.2020/

5. Ministry of Agriculture, Food and Forestry, "Agrarian Statistics" Department, Agrarian Reports from 2011- https://www.mzh.government.bg/bg/politiki-i-programi/otcheti-i-dokladi/agrarendoklad/01.09.2020/

6. Ministry of Agriculture, Food and Forestry, "Agrarian Statistics" Department, Agrarian Reports from 2012- https://www.mzh.government.bg/bg/politiki-i-programi/otcheti-i-dokladi/agrarendoklad/01.09.2020/

7. Ministry of Agriculture, Food and Forestry, "Agrarian Statistics" Department, Agrarian Reports from 2013- https://www.mzh.government.bg/bg/politiki-i-programi/otcheti-i-dokladi/agrarendoklad/01.09.2020/ 
8. Ministry of Agriculture, Food and Forestry, "Agrarian Statistics" Department, Agrarian Reports from 2014- https://www.mzh.government.bg/bg/politiki-i-programi/otcheti-i-dokladi/agrarendoklad/01.09.2020/

9. Ministry of Agriculture, Food and Forestry, "Agrarian Statistics" Department, Agrarian Reports from 2015- https://www.mzh.government.bg/bg/politiki-i-programi/otcheti-i-dokladi/agrarendoklad/01.09.2020/

10. Ministry of Agriculture, Food and Forestry, "Agrarian Statistics" Department, Agrarian Reports from 2016- https://www.mzh.government.bg/bg/politiki-i-programi/otcheti-i-dokladi/agrarendoklad/01.09.2020/

11. Ministry of Agriculture, Food and Forestry, "Agrarian Statistics" Department, Agrarian Reports from 2017- https://www.mzh.government.bg/bg/politiki-i-programi/otcheti-i-dokladi/agrarendoklad/

12. Ministry of Agriculture, Food and Forestry, "Agrarian Statistics" Department, Agrarian Reports from 2018- https://www.mzh.government.bg/bg/politiki-i-programi/otcheti-i-dokladi/agrarendoklad/01.09.2020/

13. Ministry of Agriculture, Food and Forestry, "Agrarian Statistics" Department, Agrarian Reports from 2019- https://www.mzh.government.bg/bg/politiki-i-programi/otcheti-i-dokladi/agrarendoklad/01.09.2020/ 